\title{
Water Ingestion Reduced Exhaled Nitric Oxide in the Course of the Osmopressor Response
}

\author{
You-Hsiang Chu', Herng-Sheng Lee ${ }^{2}$, Shung-Tai Ho ${ }^{3}$, Che-Se Tung ${ }^{4}$, Ching-Jiunn Tseng ${ }^{5}$, Meng-Hung Lee ${ }^{6}$ and Chih-Cherng Lu
}

${ }^{1}$ Graduate Institute of Life Sciences, National Defense Medical Center, Taiwan

${ }^{2}$ Department of Pathology, Tri-Service General Hospital, Taiwan

${ }^{3}$ Department of Anesthesiology, Taipei Veterans General Hospital/National Defense Medical Center, Taiwan

${ }^{4}$ Department of Physiology, National Defense Medical Center, Taiwan

${ }^{5}$ Department of Education and Research, Kaohsiung Veterans General Hospital, Taiwan, Republic of China

${ }^{6}$ Chang Gung University, Tao-Yuan, Taiwan

\begin{abstract}
Water ingestion induces a robust increase in blood pressure (BP) and vascular resistance in patients with an impaired efferent baroreflex. The mild pressor response was also present in elderly healthy subjects; however, there was no change in arterial blood pressure and notably no change, or even a slight reduction in heart rate in young healthy subjects. Nitric oxide (NO) has emerged as a major regulator mechanism of the cardiovascular system and the stressful situation has been linked to a reduction in serum NO. Thus we hypothesized that the exhaled nitric oxide(eNO) might be feasible to be a biomarker that can aid in the research of the osmopressor responses. The purpose of the present study was to examine whether the non-invasive monitor of eNO could reflect the osmopressor response after water ingestion. In a randomized, controlled, crossover fashion, 34 young healthy subjects (age, 22-35 years) ingested either 500 or 50 $\mathrm{mL}$ of water. Heart rate, BP, cardiac index, and total peripheral vascular resistance were measured using a Finometer hemodynamic monitor. eNO was determined by a chemiluminescence analyser before and after subjects ingested either 500 or $50 \mathrm{~mL}$ of water. Blood sampling for plasma osmolality was performed at 5 min before and at 25 min after either the water ingestion or control session. At $25 \mathrm{~min}$ after the ingestion of $500 \mathrm{~mL}$ of water, total peripheral resistance increased significantly, and plasma osmolality decreased. eNO decreased significantly at 25 min after ingestion of 500 $\mathrm{mL}$ water. This study suggests that water ingestion induced decrease of the eNO might be used as a novel biological marker in the course of the osmopressor response.
\end{abstract}

Keywords: Water ingestion; Osmopressor response; Exhaled nitric oxide (eNO); Heart rate

\section{Introduction}

Previous studies in patients with an impaired efferent baroreflex led us to discover that water ingestion induces a robust increase in blood pressure (BP) and vascular resistance [1,2]. The driving force for this increased vascular tone is not known but is likely to be magnified by the lack of baroreflex buffering capacity resulting from their autonomic failure. Water ingestion induces a profound increase in systolic BP averaging approximately $40 \mathrm{mmHg}$ in patients with autonomic failure and also elevated BP of approximately $11 \mathrm{mmHg}$ in elderly subjects. Water induces a rise in peripheral vascular resistance and a reduction in skin blood flow at 20 to 25 min after ingestion without an associated increase in BP in young healthy subjects [3-5]. This vascular effect appears within $10 \mathrm{~min}$, is maximal at $25-40 \mathrm{~min}$, and largely dissipates by $90 \mathrm{~min}$ after water ingestion [2]. This prominent vascular response after water ingestion is termed the osmopressor response (OPR).

Our previous study demonstrated that water ingestion reduce the skin blood flow, which provide a relative index of the rise in the cutaneous arteriolar tone, with rise of total peripheral vascular resistance. Recent study demonstrated that nitric oxide (NO) might involve in the postural orthostatic tachycardia syndrome (POTS) [6,7]. Both excessive NO-mediated dilation and decreased neuronal NO activity have been reported in POTS. Given the evidence suggesting that NO tonically inhibits sympathetic tone, a decrease in NO func $\neg$ tion in POTS could contribute to the hyperadrenergic state seen in this disorder.

Nitric oxide (NO) is one of the most important metabolic modulators of blood pressure and cardiovascular function in healthy subjects [7]. This has emerged as a major regulator mechanism of the cardiovascular system and the stressful situation has been linked to a reduction in serum NO. Theexhaled nitric oxide (eNO) has been popular used readily as a biomarker of vasodilatation in the study of blood pressure control in humans. Breath measurement of the eNO is available to provide a relative index of $\mathrm{NO}$ production from the vascular endothelial cells, which diffuses into the alveolar space and makes up an important part of the lower respiratory tract NO. The change of the eNO might be implicated as a biomarker of vascular endothelial response in the osmopressor response in young healthy subjects $[8,9]$.

We hypothesized that the eNO might be useful as a biomarker and aid in the clinical research of the osmopressor response. We try to evaluate whether the non-invasive monitor of eNO is feasible to be used as a physiological marker in the osmopressor response. Our present study has shown that there was a consistent relationship between the

*Corresponding author: Chih-Cherng Lu, Associate Professor, Department of Anesthesiology, Taipei Veterans General Hospital /National Defense Medical Center 3 F, Chung-Cheng Building, No. 201, Sec 2, Shipai Rd, Beitou District, Taiwan, Tel: 886-2-2875-7549; Fax: 886-2-2875-1597; E-mail: x5183@ms45.hinet.net

Received August 29, 2013; Accepted October 18, 2013; Published October 21,2013

Citation: You-Hsiang C, Herng-Sheng L, Shung-Tai Ho, Che-Se T, Ching-Jiunn T, et al. (2013) Water Ingestion Reduced Exhaled Nitric Oxide in the Course of the Osmopressor Response. J Hypertens 2: 129. doi:10.4172/2167-1095.1000129

Copyright: () 2013 You-Hsiang C, et al. This is an open-access article distributed under the terms of the Creative Commons Attribution License, which permits unrestricted use, distribution, and reproduction in any medium, provided the original author and source are credited. 
reductions of eNO and heart rate in the course of the osmopressor response.

\section{Methods}

This study was approved by the Institutional Review Board (098032-312) of Tri-Service General Hospital, Taipei, Taiwan and was performed in the Pain Department Laboratory. Informed consent was obtained from each volunteer. We studied 34 healthy normal young adults who had no history of syncope and who were currently using no prescription or over-the-counter medications.

\section{Study Protocol}

The subjects were asked to empty their bladder before beginning the test to avoid any effect of the urinary bladder or stomach distension, which are known to affect peripheral sympathetic activity. Study sessions took place in a quiet, dimly lit room at a comfortable ambient temperature $\left(21-24^{\circ} \mathrm{C}\right)$. We used a randomized, crossover study design. We used a randomized, crossover study design. Each subject underwent the study protocol twice on separate days. Subjects received either $500 \mathrm{~mL}$ or $50 \mathrm{~mL}$ water in their initial study, with the alternative in their second test. As water ingestion increases total systemic vascular resistance in healthy young subjects within $5 \mathrm{~min}$ after ingestion, reaches a maximum in 20-40 min, and is maintained for more than $1 \mathrm{~h} \mathrm{[2]}$, the 25-min time point after water ingestion was taken as representative of the maximal osmopressor response in comparison with the baseline level before water ingestion.

\section{Instrumentation}

An antecubital venous catheter was inserted for blood sampling at least $15 \mathrm{~min}$ before the beginning of the test, with the patient in the sitting position. Hemodynamic parameters including heart rate (HR), BP, stroke volume (SV), cardiac index (CI), and total peripheral vascular resistance (TPR) were measured using a Finometer (FMS, Finapres Measurement Systems, Arnhem, The Netherlands) [10-12]. Computation of stroke volume and cardiac output using the Model flow method was based on the finger arterial pressure [13]. The hemodynamic parameters were determined by the calculation of one minute average from the continuous recording of Finometer. Skin blood flow (SkBF) was recorded and measured using a flowmeter (DRT4 Instrument, Moor Instrument, Axminster, UK) over the right palmar region [14].

\section{Exhaled nitric oxide measurement}

Exhaled NO was measured at 50, 100 and $200 \mathrm{mLs}^{-1}$ with a chemiluminescence analyser (NIOX; Aerocrine AB, Solna, Sweden), according to current recommendations [15]. Estimation of alveolar and bronchial contributions to exhaled NO was made by the slopeintercept model [16] using all the above-mentioned flow-rates. The correction of alveolar $\mathrm{NO}$ values for axial diffusion was made using the equation CalvNOadj $\left.=\left(\mathrm{Calv}_{\mathrm{NO}}\right) \times 0.08 \times \mathrm{eNO} \times 0.05\right) / 0.92$, according to Bucca et al. [17].

\section{Blood sampling for plasma osmolality}

Blood samples $(2 \mathrm{~mL})$ were collected at time points of $-5 \mathrm{~min}$ (baseline) and $25 \mathrm{~min}$ after water ingestion. Plasma osmolality was analyzed by the freezing point depression method using an Advanced osmometer model 3900 (Advanced Instruments, Norwood, MA, USA) [18].

\section{Statistical Analysis}

A sample size of 34 was estimated to have $95 \%$ power to detect an effect size of 0.8 by the paired t-test with a two-sided significance level of 0.05 [19]. Values are reported as mean \pm standard deviation. P-values of $<0.05$ were considered significant, and all tests were two-tailed. Statistical analyses were performed using SPSS ver. 13.0 software (SPSS Inc., Chicago, IL, USA).

\section{Results}

Demographic data, basal hemodynamic variables and plasma osmolality for all 34 subjects are shown in Table 1 .

\section{Hemodynamic variables}

Twenty-five minutes after ingesting $500 \mathrm{~mL}$ of water, HR decreased significantly from $72.8 \pm 9.4 \mathrm{bpm}$ at baseline to $66.4 \pm 7.8 \mathrm{bpm}$ after ingesting $500 \mathrm{~mL}$ of water $(\mathrm{p}<0.0001)$. CI decreased significantly from $3.31 \pm 0.50 \mathrm{~L} / \mathrm{min} / \mathrm{m} 2$ at baseline to $3.04 \pm 0.47 \mathrm{~L} / \mathrm{min} / \mathrm{m}^{2}(p=0.0041)$ after ingesting $500 \mathrm{~mL}$ of water. Twenty-five minutes after ingesting 500 $\mathrm{mL}$ water, TPR increased significantly from $1342 \pm 240$ dyne $\cdot \mathrm{s} \cdot \mathrm{cm}^{-5}$ at baseline to $1732 \pm 374$ dyne $\cdot \mathrm{sec} \cdot \mathrm{cm}^{-5}(\mathrm{p}<0.0001)$. Ingestion of 500 $\mathrm{mL}$ of water decreased the SkBF from $196.7 \pm 89.3$ perfusion units at baseline to $93.9 \pm 92.8$ perfusion units $(\mathrm{p}<0.0001$; Table 2$)$.

\section{Change in plasma osmolality after water ingestion}

There was statistical significant difference in the plasma osmolality between the water-ingesting $(500 \mathrm{~mL})$ and control $(50 \mathrm{~mL})$ sessions at 25 th min after water ingestion ( $\mathrm{p}=0.0003$; Figure 1) Ingestion of 500 $\mathrm{mL}$ of water lowered plasma osmolality from $284.3 \pm 4.2 \mathrm{mOsm} / \mathrm{kg}$ at baseline to $280.5 \pm 4.0 \mathrm{mOsm} / \mathrm{kg}$ at $25^{\text {th }} \mathrm{min}$ after water ingestion $(\mathrm{p}=0.0001)$. There was statistical significant difference in the eNO between the water-ingesting $(500 \mathrm{~mL})$ and control $(50 \mathrm{~mL})$ sessions at $25^{\text {th }}$ min after water ingestion $(p=0.0475$; Figure 2$)$. Ingestion of 500 $\mathrm{mL}$ of water lowered eNO from $14.75 \pm 1.91$ at baseline to $14.19 \pm 1.97$ $\mu \mathrm{M}$ at 25 th $\mathrm{min}$ after water ingestion $(\mathrm{p}=0.0467)$. Figure 3 displayed a good correlation between the decrease of exhaled nitric oxide $(\triangle \mathrm{eNO})$ and heart rate $(\Delta \mathrm{HR})$ at the $25^{\text {th }}$ minute after ingestion of $500 \mathrm{~mL}$ water $\left(r^{2}=0.5065 ; p=0.007\right)$. Figure 4 displayed no statistical significant correlation between the increase of total peripheral vascular resistance and decrease of the plasma osmolality at the 25th minute after ingestion of $500 \mathrm{~mL}$ water $(\mathrm{r}=0.2511 ; \mathrm{p}=0.1656)$.

\begin{tabular}{|c|c|c|}
\hline & Mean \pm SD & Range \\
\hline Age, year & $25.79 \pm 2.99$ & $22 \sim 35$ \\
\hline Gender, male: female & $9: 25$ & \\
\hline Weight, kg & $58.88 \pm 7.56$ & $45 \sim 80$ \\
\hline Height, cm & $164.9 \pm 7.42$ & $147 \sim 182$ \\
\hline Body-mass index, $\mathrm{kg} / \mathrm{m}^{2}$ * & $21.64 \pm 1.80$ & $17.84 \sim 26.0$ \\
\hline \multicolumn{3}{|l|}{ Blood pressure, $\mathrm{mmHg}$} \\
\hline Systolic & $118.3 \pm 10.52$ & $93 \sim 142$ \\
\hline Diastolic & $69.2 \pm 6.26$ & $55 \sim 88$ \\
\hline Heart rate, beats/min & $72.5 \pm 8.46$ & $56 \sim 97$ \\
\hline Cardiac index, L/min $/ \mathrm{m}^{2}$ & $3.3 \pm 0.48$ & $2.36 \sim 4.31$ \\
\hline Stroke volume, mL & $77.0 \pm 14.09$ & $54 \sim 120$ \\
\hline \multicolumn{3}{|l|}{ Plasma, } \\
\hline Osmolality, mOsmo/Kg & $284.4 \pm 0.87$ & $272.0 \sim 291.0$ \\
\hline Hct, \% & $38.8 \pm 4.67$ & $30.0 \sim 52.0$ \\
\hline TPR, dyne•sec ${ }^{\circ} \mathrm{cm}^{-5}$ & $1345 \pm 228.2$ & 955 2042 \\
\hline SkBF, perfusion units & $186.4 \pm 92.9$ & $13.1 \sim 395.0$ \\
\hline
\end{tabular}

*The bodymass index is the weight in kilograms divided by the square of the height in meters.

Table 1: Characteristics of the 34 subjects examined at $5 \mathrm{~min}$ (baseline) before water ingestion. TPR, total peripheral vascular resistance; SkBF, laser Doppler skin blood flow. 
Citation: You-Hsiang C, Herng-Sheng L, Shung-Tai Ho, Che-Se T, Ching-Jiunn T, et al. (2013) Water Ingestion Reduced Exhaled Nitric Oxide in the Course of the Osmopressor Response. J Hypertens 2: 129. doi:10.4172/2167-1095.1000129

\begin{tabular}{|c|c|c|c|c|}
\hline & \multicolumn{2}{|c|}{ Water $50 \mathrm{~mL}$} & \multicolumn{2}{|c|}{ Water $500 \mathrm{~mL}$} \\
\hline & Baseline & $25 \mathrm{~min}$ & Baseline & $25 \mathrm{~min}$ \\
\hline Heart rate, & $72.2 \pm 7.5$ & $69.2 \pm 8.2$ & $72.8 \pm 9.4$ & $66.4 \pm 7.8^{* *}$ \\
\hline \multicolumn{5}{|l|}{ beats/min } \\
\hline SBP, mmHg & $118.4 \pm 11.2$ & $126.6 \pm 10.7$ & $118.3 \pm 10.0$ & $122.3 \pm 10.0$ \\
\hline DBP, mmHg & $69.5 \pm 6.5$ & $75.1 \pm 6.8$ & $66.9 \pm 6.1$ & $77.3 \pm 7.4$ \\
\hline MABP, & $90.1 \pm 7.2$ & $98.7 \pm 9.2$ & $90.4 \pm 6.6$ & $100.8 \pm 7.3$ \\
\hline \multicolumn{5}{|l|}{$\mathrm{mmHg}$} \\
\hline $\mathrm{SV}, \mathrm{mL} / \mathrm{min}$ & $76.7 \pm 11.8$ & $75.6 \pm 12.8$ & $77.2 \pm 16.2$ & $75.3 \pm 14.3$ \\
\hline $\mathrm{Cl}, \mathrm{L} / \mathrm{min} / \mathrm{m}^{2}$ & $3.31 \pm 0.47$ & $3.10 \pm 0.48$ & $3.31 \pm 0.50$ & $3.04 \pm 0.47^{* *}$ \\
\hline TPR, & $1348 \pm 219.0$ & $\begin{array}{c}1556 \pm \\
305.6\end{array}$ & $1342 \pm 240.3$ & $1732 \pm 373.7^{* *}$ \\
\hline \multicolumn{5}{|l|}{ dyne $\cdot \mathrm{sec}^{\circ} \mathrm{cm}^{-5}$} \\
\hline SkBF, & $176.0 \pm 96.6$ & $123.7 \pm 87.0$ & $196.7 \pm 89.3$ & $93.9 \pm 92.8^{\star *}$ \\
\hline \multicolumn{5}{|l|}{ perfusion units } \\
\hline \multicolumn{5}{|c|}{ Plasma Osmolaity } \\
\hline Osmalility, mo & $284.4 .0 \pm 0.66$ & $283.5 \pm 0.66$ & $284.3 \pm 0.75$ & $280.5 \pm 0.71^{* *}$ \\
\hline $\mathrm{mOsmo} / \mathrm{Kg}$ & & & & \\
\hline
\end{tabular}

Values are the mean (SD); SBP, systolic blood pressure; DBP, diastolic blood pressure; MABP, mean arterial blood pressure; SV, stroke volume; $\mathrm{Cl}$, cardiac index; TPR, total peripheral vascular resistance; SkBF, laser Doppler skin blood flow

${ }^{* *} p<0.01$ indicates a significant difference between the baseline $(-5$ minutes prior to water ingestion) and 25 minutes after ingestion of $500 \mathrm{~mL}$ water

Table 2: Hemodynamic variables at 5 min before (baseline), 25 min after ingestion of either 50 or $500 \mathrm{~mL}$ of water in the same subjects. $(n=34)$.

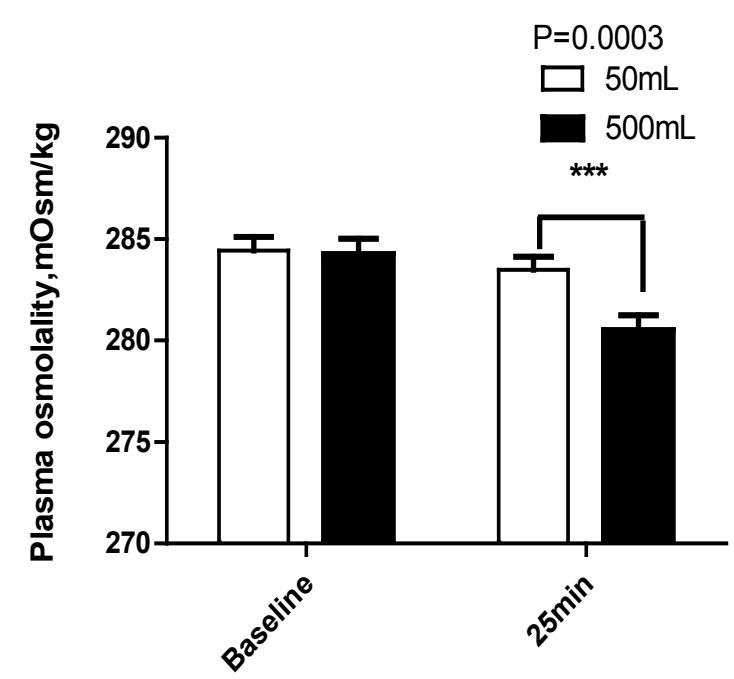

Figure 1: There was significant different in plasma osmolality between 50 and $500 \mathrm{~mL}$ of water ingestion at a time point 25 min after ingestion $(\mathrm{p}=0.0003)$. Change of plasma osmolality from the baseline $(-5 \mathrm{~min}$ before and $25 \mathrm{~min}$ after either ingestion $500 \mathrm{~mL}(\bullet)$ or $50 \mathrm{~mL}$ ( $\square$ ) of water. The bars indicate mean $\pm S D(n=34)$

\section{Discussion}

This study first demonstrated water ingestion reduces the exhaled nitric oxide which could possibly be used as a biological marker in course of the osmopressor response. Second, water ingestion significant lowers the plasma osmolality at the $25^{\text {th }}$ min after ingestion of $500 \mathrm{~mL}$ water. Third, water increases total peripheral vascular resistance and also reduces the palmar skin blood flow. Forth, water ingestion reduces heart rate in associated with the reduction of exhaled nitric oxide at the maximal phase of osmopressor response.

$\mathrm{NO}$ is one of the most important metabolic modulators of blood

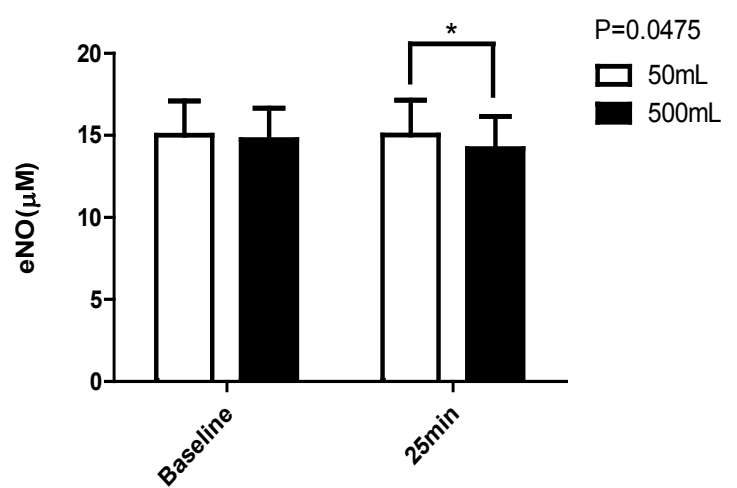

Figure 2: There was significant different in exhaled nitric oxide (eNO) between 50 and $500 \mathrm{~mL}$ of water ingestion at a time point 25 min after ingestion $(p=0.0475)$. Change of the eNO concentration from the baseline ( $-5 \mathrm{~min}$ before) and $25 \mathrm{~min}$ after either ingestion $500 \mathrm{~mL}(\square)$ or $50 \mathrm{~mL}$ (口) of water. The bars indicate mean \pm SEM $(n=34)$.

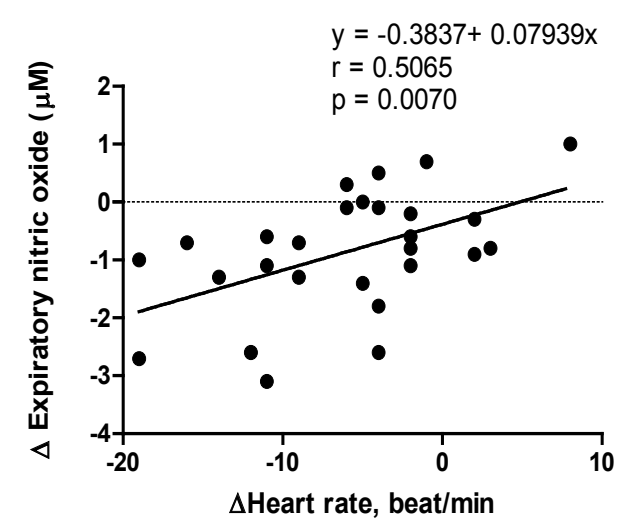

Figure 3: There was a significant correlation between the decrease of heart rate $(\Delta \mathrm{HR})$ and exhaled nitric oxide $(\Delta \mathrm{eNO})$ at the $25^{\text {th }}$ minute after ingestion of $500 \mathrm{~mL}$ water $(r=0.5065 ; p=0.007)$.

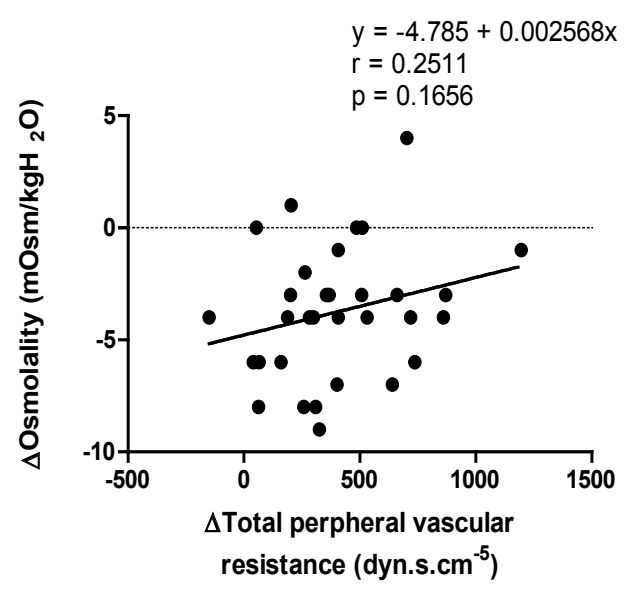

Figure 4: There was no significant correlation between the decrease of plasma osmolality and increase of total peripheral vascular resistance at $25^{\text {th }}$ min after ingestion of $500 \mathrm{~mL}$ water $(r=0.2511 ; p=0.1656)$. 
pressure and cardiovascular function. Recent studies demonstrated that the sympathetically mediated hyper $\neg$ tension caused by chronic inhibition of NO. NO tonically restrains blood pressure by at least 30 $\mathrm{mmHg}$ in healthy subjects. The mechanisms by which NO tonically decreases blood pressure includes a direct vasodilatory action and inhibition of sympathetic nervous system tone [20]. The advantage of breath analysis of eNO offer relatively inexpensive, rapid, noninvasive methods for detecting and/or monitoring a variety of physiological response. This simple measurement of eNO could provide reference for the medical applications with specific attention to applications (and potential applications) in water therapy for autonomic disorder. Thus, we suggested that the exhaled NO could be used as biomarkers in the research of the osmopressor response.

Consistent with the previous studies, the present study showed that ingesting water produces a reduction in heart rate in simultaneously increase sympathetic vasoconstriction. This suggested the water ingestion increases the cardiovagal tone simultaneously to buffer the sympathetic vasoconstriction and leads to no apparent change in blood pressure in young healthy subject. The osmopressor response, despite increases in sympathetic vasoconstrictor discharge and peripheral resistance, blood pressure remains stable, have been suggested to be a result of a vagally mediated fall in cardiac output. The fall in cardiac output is likely to be mediated by reductions in both heart rate and stroke volume, as this vagal response has also been observed in both humans and animal subjects $[4,14,21]$.

Our results suggest that the physiological response to water drinking in healthy subjects may be an integrated response, consisting of an increase in sympathetic vasoconstrictor activity coupled with a parallel increase in cardiac vagal tone. Such an autonomic response is unusual, since under most circumstances sympathetic and parasympathetic outflows are inversely related. The osmopressor response is similar in some respects to the 'diving reflex' in which trigeminal nerve stimulation by cold results in cardiac vagal activation and a profound bradycardia, as well as sympathetic activation and vasoconstriction [22]. The bradycardic response following water ingestion appears to have a slow increase in magnitude and a slow decay, a pattern more characteristic of a response have been thought to be driven by the stimulation of water's hypoosmolality $[11,12]$.

To our knowledge, the actual site and type of stimulus that elicits the OPR remains controversial. Several potential stimuli have been considered including duodenal stretch, vasoactive hormones, osmotic factors, and the change in plasma volume after water ingestion. Jordan et al. found no measurable changes in plasma vasopressin at 30 and 60 min after subjects drank $500 \mathrm{~mL}$ of water and concluded that vasopressin did not participate in the OPR $[23,24]$. Hydration status may affect $\mathrm{BP}$, but acutely increasing plasma volume via an intravenous saline infusion fails to elicit the pressor response seen with duodenal water administration $[25,26]$. The absence of a pressor response following a saline infusion via nasogastric tube makes luminal stretch an unlikely explanation for the increase in $\mathrm{BP}$ or osmopressor response to water because both fluids would induce an equal duodenal stretch. In fact, it is not easy to investigate how water affects luminal osmolality of the gastrointestinal tract in humans. There was an animal study provides evidence that duodenal infusion of water produces relative hypo-osmolality in the portal circulation, which indicates the hypoosmotic nature of water $[27,28]$. Our present study also demonstrated that a water-induced decrease in plasma osmolality was associated with the elicitation of the OPR. Thus, the maximal effect of the OPR that occurred through a decrease in plasma osmolality after water ingestion suggests that the hypo-osmolality of water acted as a major afferent stimulus.

Drinking water increases leg vascular resistance and TPR in healthy young subjects proportional to the increase in muscle sympathetic nerve activity of nerves supplying the calf region [4]. Our present study demonstrated that ingesting water induces sympathetic vasoconstriction associated with a decrease in palmar SkBF, which could be a characteristic of the OPR in young healthy subjects [14]. Direct evidence for sympathetic vasoconstrictor activation after water ingestion is an increase in muscle sympathetic nerve activity [4] Compared with the elderly or those patients with autonomic failure, ingestion of $500 \mathrm{~mL}$ water does not lead to a rise in arterial blood pressure, which is in keeping with the results of previous investigators who, despite convincingly demonstrating a rise in sympathetic vasoconstrictor activity, found no rise in arterial blood pressure [2,11]. Consistent with these previous studies, the present study showed that ingesting water produced a maximal rise in TPR and an apparent decrease in SkBF without a prominent change in BP [14].

The physiological response to in normal subjects appears to be complex, involving both limbs of the autonomic nervous system $[29,30]$. Further investigations are required to define this response in detail. Only when the normal response to water drinking is clearly understood will be able to explain the powerful and potentially useful effects of water ingestion on blood pressure in subjects with autonomic dysfunction.

In conclusion, this study first demonstrated water reduce the eNO in accompany with slightly bradycardia might explain the complex pattern of the osmopressor response, which may involve both limbs of sympathetic and parasympathetic nervous activating system. We suggest that the eNO could be used as a biological marker in the course of the osmopressor response as a reflection of sympathetic activation of osmopressor response. The molecular basis of water ingestion lower the eNO in the osmopressor response need to be clarified in the future experiment.

\section{Perspectives}

Ingestion of water is proven to be therapeutic to relieve debilitating hypotension episodes. Identifying the exact mechanism of waterinduced sympathetic activation may provide novel targets for treating orthostatic and vasovagal syncope. The osmopressor response linked to eNO is a new molecular candidate to implicate the physiology of autonomic cardiovascular regulation in humans.

\section{Acknowledgments}

Financial support was provided by a government grant (NSC99-2314-B-016012MY3) from the National Science Council, Taiwan.

\section{References}

1. Lu CC, Diedrich A, Tung CS, Paranjape SY, Harris PA, et al. (2003) Water ingestion as prophylaxis against syncope. Circulation 108: 2660-2665.

2. Jordan J, Shannon JR, Black BK, Ali Y, Farley M, et al. (2000) The pressor response to water drinking in humans : a sympathetic reflex? Circulation 101 504-509.

3. Scott EM, Greenwood JP, Stoker JB, Gilbey SG, Mary DA (2000) Water drinking and sympathetic activation. Lancet 356: 2013.

4. Scott EM, Greenwood JP, Gilbey SG, Stoker JB, Mary DA (2001) Water ingestion increases sympathetic vasoconstrictor discharge in normal human subjects. Clin Sci (Lond) 100: 335-342.

5. Schroeder C, Bush VE, Norcliffe LJ, Luft FC, Tank J, et al. (2002) Wate drinking acutely improves orthostatic tolerance in healthy subjects. Circulation 106: $2806-2811$. 
Citation: You-Hsiang C, Herng-Sheng L, Shung-Tai Ho, Che-Se T, Ching-Jiunn T, et al. (2013) Water Ingestion Reduced Exhaled Nitric Oxide in the Course of the Osmopressor Response. J Hypertens 2: 129. doi:10.4172/2167-1095.1000129

Page 5 of 5

6. Garland EM, Winker R, Williams SM, Jiang L, Stanton K, et al. (2005) Endothelial NO synthase polymorphisms and postural tachycardia syndrome. Hypertension 46: 1103-1110.

7. Gamboa A, Okamoto LE, Raj SR, Diedrich A, Shibao CA, et al. (2013) Nitric oxide and regulation of heart rate in patients with postural tachycardia syndrome and healthy subjects. Hypertension 61: 376-381.

8. Singh S, Evans TW (1997) Nitric oxide, the biological mediator of the decade: fact or fiction? Eur Respir J 10: 699-707.

9. Adachi H, Oshima S, Sakurai S, Toyama T, Hoshizaki H, et al. (2003) Nitric oxide exhalation correlates with ventilatory response to exercise in patients with heart disease. Eur J Heart Fail 5: 639-643.

10. Li MH, Chen PH, Ho ST, Tung CS, Lin TC, et al. (2013) Lower body negative pressure-induced vagal reaction: role for the osmopressor response? Am J Hypertens 26: 5-12.

11. Chu YH, Hsu YJ, Lee HS, Ho ST, Tung CS, et al. (2013) The osmopressor response is linked to upregulation of aquaporin-1 tyrosine phosphorylation on red blood cell membranes. Hypertension 62: 197-202.

12. Chu H, Chu YH, Lee HS, Ho ST, Tung CS, et al. (2013) Salivary alpha-amylase as a biomarker for the osmopressor response in healthy adults. Biomarkers 18: $509-515$.

13. Guelen I, Westerhof BE, Van Der Sar GL, Van Montfrans GA, Kiemeneij F et al. (2003) Finometer, finger pressure measurements with the possibility to reconstruct brachial pressure. Blood Press Monit 8: 27-30.

14. Lu CC, Li MH, Lin TC, Chen TL, Chen RM, et al. (2012) Water ingestion reduces skin blood flow through sympathetic vasoconstriction. Clin Auton Res 22: 63-69.

15. American Thoracic Society; European Respiratory Society (2005) ATS/ERS recommendations for standardized procedures for the online and offline measurement of exhaled lower respiratory nitric oxide and nasal nitric oxide, 2005. Am J Respir Crit Care Med 171: 912-930.

16. Tsoukias NM, Tannous Z, Wilson AF, George SC (1998) Single-exhalation profiles of $\mathrm{NO}$ and $\mathrm{CO} 2$ in humans: effect of dynamically changing flow rate. $J$ Appl Physiol (1985) 85: 642-652.

17. Bucca C, Cicolin A, Guida G, Heffler E, Brussino L, et al. (2012) Exhaled nitric oxide (FENO) in non-pulmonary diseases. J Breath Res 6: 027104.
18. Lu CC Li MH, Ho ST, Lu CL, Lin JC, et al. (2008) Glucose reduces the effect of water to promote orthostatic tolerance. Am J Hypertens 21: 1177-1182.

19. Faul F, Erdfelder E, Buchner A, Lang AG (2009) Statistical power analyses using $\mathrm{G}^{*}$ Power 3.1: tests for correlation and regression analyses. Behav Res Methods 41: 1149-1160.

20. Sander M, Hansen PG, Victor RG (1995) Sympathetically mediated hypertension caused by chronic inhibition of nitric oxide. Hypertension 26: 691-695.

21. Endo Y, Torii R, Yamazaki F, Sagawa S, Yamauchi K, et al. (2001) Water drinking causes a biphasic change in blood composition in humans. Pflugers Arch 442: 362-368.

22. Alboni P, Alboni M, Gianfranchi L (2011) Diving bradycardia: a mechanism of defence against hypoxic damage. J Cardiovasc Med (Hagerstown) 12: 422-427.

23. Jordan J (2002) Acute effect of water on blood pressure. What do we know? Clin Auton Res 12: 250-255.

24. Jordan J, Shannon JR, Grogan E, Biaggioni I, Robertson D (1999) A potent pressor response elicited by drinking water. Lancet 353: 723

25. Raj SR, Biaggioni I, Black BK, Rali A, Jordan J, et al. (2006) Sodium paradoxically reduces the gastropressor response in patients with orthostatic hypotension. Hypertension 48: 329-334.

26. Lipp A, Tank J, Franke G, Arnold G, Luft FC, et al. (2005) Osmosensitive mechanisms contribute to the water drinking-induced pressor response in humans. Neurology 65: 905-907.

27. McHugh J, Keller NR, Appalsamy M, Thomas SA, Raj SR, et al. (2010) Porta osmopressor mechanism linked to transient receptor potential vanilloid 4 and blood pressure control. Hypertension 55: 1438-1443.

28. May M, Jordan J (2011) Theosmopressor response to water drinking. Am J Physiol Regullntegr Comp Physiol 300: R40-46.

29. Menani JV, Saad WA, Camargo LA, Antunes-Rodrigues J, Covian MR, et al (1984) Effect of cholinergic and adrenergic stimulation of the subfornical organ on water intake. Pharmacol Biochem Behav 20: 301-306.

30. Barbosa SP, de Gobbi JI, Zilioli L, Camargo LA, Saad WA, et al. (1995) Role of cholinergic and adrenergic pathways of the medial septal area in the water intake and pressor response to central angiotensin II and carbachol in rats. Brain Res Bull 37: 463-466. 